Providing an explanation for service failure: context, content and customer responses ${ }^{1}$

Authors:

Dr Beverley Sparks, Professor

Service Industry Research Centre and

Department of Tourism, Leisure, Hospitality and Sport Management,

Griffith University, PMB 50, Gold Coast, Queensland, Australia, 9726

Email: b.sparks@griffith.edu.au

Telephone: +61755528766

Dr Liz Fredline, Senior Research Fellow, Sustainable Tourism CRC \&

Department of Tourism, Leisure, Hospitality \& Sport Management

Griffith University, PMB 50, Gold Coast, Queensland, Australia, 9726

${ }^{1}$ This paper is based on a research project funded by Griffith University's Department of Tourism, Leisure, Hospitality and Sport Management. We acknowledge the work of Carmel Tideswell in the early phases of this research. 


\title{
Providing an explanation for service failure: context, content and customer responses
}

\begin{abstract}
This study investigated the role of explanations or accounts in mitigating the impact of service failure on customer satisfaction and loyalty in a hospitality context. The study used a between-groups experimental design with different scenarios, which were presented to a sample of experienced hotel customers via a postal survey. The scenarios differed in terms of the severity of the service failure, the type of explanation (referential or justification) and the thoroughness of the explanation. The results suggest that referential explanations were associated with higher levels of satisfaction and loyalty than justifications, when the service failure was severe. Evidence was also found that account adequacy was an important mediator for the effect of thoroughness on satisfaction.
\end{abstract}

Key words: explanations; social accounts; explanation adequacy; service failure; service recovery; 


\section{INTRODUCTION}

Like all service industries, the services provided within the hospitality sector have several things in common which distinguish them from the products offered by manufacturing and other commercial sectors. These services are relatively intangible, and are characterised by simultaneous production and consumption. Thus, it is difficult to observe hospitality services in advance and even harder to 'try before you buy'. The provision of hospitality services is often immediate and spontaneous, relying on experiential aspects for consumer evaluation. For all of these reasons, achieving a situation of zero defects is difficult, perhaps even impossible. While striving toward reducing the number of service failures remains an important goal, it is also important for hospitality and other service industries to investigate the best methods for recovering from service failure events.

One way to deal with service failure events is to provide an explanation to the aggrieved consumer as a way of decreasing negative perceptions of the firm. Despite the importance of explanations as a way to mitigate the negative effects of a service failure, relatively little research has been conducted into what works best and under what circumstances. This paper documents a scenariobased study aimed at investigating the role of accounts, or explanations ${ }^{2}$, in the management of a hospitality service failure event. Two different types of explanations identified from the literature, justification and referential, were examined in an experimental research design, which also manipulated the severity of the failure and the thoroughness of the account. The aim was to gain insight into the effectiveness of different types of explanations and, more specifically, to examine how the impact of explanations on customer satisfaction and intended loyalty varies with content (e.g., account thoroughness) and contextual (e.g., failure severity) variables.

\footnotetext{
${ }^{2}$ Note: we use the terms account and explanation interchangeably in this paper.
} 


\section{Literature}

Service failure, or service breakdown, can be defined as that service which does not meet the customer's expectations. There are several responses that customers may have to service failure or poor service recoveries. The most widely researched are satisfaction responses, emotional reactions (such as anger, disappointment or regret), and behavioral responses (such as complaining, exiting or switching behaviors). Satisfaction is a widely researched consumer evaluation because it is of the utmost importance to firms, in order to ensure sustainability. Another important behavioral consequence of service failure relates to the repatronage of particular services. The long-term loyalty of customers is likely to be affected by service failure, especially where there is opportunity to change service providers (that is, engage in switching behavior). Indeed, Keaveney (1995) found that the most frequent reason why people switched firms was the experience of service failures. In recent research, Ok and his associates (2005) demonstrated, in a restaurant setting, that the manner in which a service failure event is managed ultimately affects behavioral intentions including the likelihood of repeat visitation.

The action taken by a hospitality firm following a service failure can constitute a service recovery or, if inadequate, a second failure. The term 'service recovery' refers to the action taken by the service organization in response to a customer's expression of dissatisfaction with some aspect of the service. It is the process of dealing with a service failure situation with the aims of returning the customer to a state of satisfaction. Service recovery techniques usually involve attempts to rectify the service breakdown but may also entail providing customers with explanations about the service failure, apologizing, making offers of compensation, and being courteous in the process (see for example, Blodgett, Hill \& Tax, 1997; Butcher \& Heffermen, 2006; Karatepe, 2006; Matilla, 1999; Sparks \& Callan, 1996). This paper seeks to investigate the role of explanations in managing a service failure event. 
Research in a hospitality context suggests that individuals have a normative expectation for some sort of explanation when things go wrong (Mc Coll Kennedy \& Sparks, 2003). Indeed, Mc Coll Kennedy and Sparks (2003) found customers wanted to understand why things had failed and why specific counter measures were taken, demonstrating the perceived need for, and potential value of, providing an explanation. However, their study was silent on the types of explanations that customers might prefer and on how explanations might operate in different service failure situations. Karatepe (2006) tested the relationship of apologies and explanations as predictors of interactional justice. His research demonstrated both to be significant, although explanations only had a moderate effect. Of particular interest in Karatepe's (2006) research is that many respondents (complaining customers) specifically told the research team that they did not receive a reasonable response to their complaints. However, once again, types of explanations were not investigated. Reviews by Davidow $(2000 ; 2003)$ have highlighted the need for more research in this field. So, although it appears consumers want an explanation, there may be many factors that work toward enhancing, or otherwise, the effect of an explanation. Indeed, in a meta-analysis of the effects of explanations, Shaw and his associates (2003) state there is uncertainty about the merits of various explanation types. While explanations may take many forms - excuses, justifications, referential accounts, apologies and so on (Folger \& Cropanzano, 1998) - the efficacy of these in service failure situations is unclear.

Two of the possible explanation types were investigated in this research, namely, justifications and referential explanations. Justifications are characterized by the presentation of a set of reasons that justify the actions that led to the service failure event. They typically entail an admission of responsibility, which legitimizes the service organization's actions in terms of shared needs and/or higher goals (Folger \& Cropanzano, 1998). Bies (1987) has suggested that justifications are characterized by giving reasons for the negative outcome that might be necessary for survival. For 
example, in the tourism and hospitality industry a service failure that many people may have encountered is an airline overbooking the plane, which results in customers being unable to board a flight. The unfortunate customer is frequently given an explanation that argues an airline has to over book its seats to ensure $100 \%$ capacity is achieved. An implication of this type of explanation is that the action is defensible because, to do otherwise, would threaten the viability of the air carrier. Thus, while this action might be highly inconvenient to travelers, it is justifiable based on company survival grounds.

In contrast, referential explanations involve attempts to reframe the situation to lower the expectations of the aggrieved customer (Bies, 1987). Thus, this type of account seeks to minimize the perceived unfavorability of the failure by invoking downward comparisons (for example, reframing a situation to one where there is someone else worse off following the failure). For instance, advising a guest that they will not have to wait as long for a room as will some other guests that are arriving shortly after is an attempt to minimize customer perceptions of harm by comparing their fate to that of other guests. In such instances, the explanation points to other referential standards in an effort to reduce perceptions of severity of harm to self. But which type of explanation will be more efficacious? To date this is unknown, although some past research provides limited insight. For instance, Conlon and Murray (1996) found that explanations in which companies accepted (vs. avoided or denied) responsibility for a problem (e.g., justifications, rather than excuses) resulted in more favorable customer evaluations. This finding requires replication especially in other settings such as the hospitality industry. Our research seeks to further investigate how justifications and referential explanations impact two forms of customers' evaluations: satisfaction and loyalty.

Hypothesis 1: A referential explanation of a service failure will have a different impact on customer evaluations of customer satisfaction and intended loyalty than a justification 
In addition to the explanation type, the amount of relevant information provided may be important to a customer. That is, the thoroughness of the account has also been found to influence an explanation's effectiveness (Folger \& Cropanzono, 1998) in an organizational justice context. Therefore, thoroughness may potentially affect consumer satisfaction or loyalty. However, while past organizational research (Shapiro, Buttner, \& Barry, 1994) has argued that to be effective an account also needs to be thorough, this has not been tested in service failure situations. In the organizational literature, Greenberg (1994) found that a thorough explanation made workers more accepting of an outcome. It seems plausible that the provision of detailed information about a service failure could produce greater levels of satisfaction in an aggrieved customer and maintain loyalty. Thus, while it is important for hospitality firms to gain appreciation of how types of explanations might impact customers' satisfaction, there are other characteristics of the explanation that might influence satisfaction or loyalty.

Hypothesis 2: More thorough accounts of a service failure will result in higher levels of customer satisfaction and intended loyalty.

It is possible that thoroughness does not directly influence satisfaction levels but operates by influencing other variables. As other researchers (for example, Bobocel \& Zdaniuk, 2005) have noted, not all explanations are equal and characteristics of the explanation may be interpreted differently. In addition to the type of explanation given, it is necessary to consider the role of the recipient (customer) in the effectiveness of an explanation. That is, it is the interpretation of the explanation by the customer that may determine its effectiveness. If the customer perceives the explanation to be adequate then it is likely to be effective. Characteristics of the message, such as the amount of detail or thoroughness, may result in a more effective explanation. Shapiro and associates (1994) found that thoroughness of an 
explanation increased the perception of how adequate the explanation was, while Folger and Cropanzano (1998), in their model of accounts, suggested that explanation adequacy could mediate outcome evaluations. We further investigate this in a service failure situation to suggest account adequacy will mediate between account thoroughness and consumer satisfaction judgments.

Hypothesis 3: Perceived levels of thoroughness of a service failure explanation will significantly influence ratings of consumer satisfaction and loyalty through the mediating factor of account adequacy.

Not all service failures are equal in terms of how severe they are for the consumer. While the outcome of some service failures might be minor, for instance, a short delay in checking into a hotel room, others might be more inconvenient, such as not having a room available due to overbooking. Smith, Bolton, and Wagner (1999) refer to this as magnitude of the service failure and have demonstrated that it does moderate some aspects of the service recovery process. Using a hotel context, they found that as service failure severity got larger, service recovery tactics were less effective. Similarly, the severity of service failure may moderate how effective an explanation is in reducing consumer negative evaluations. There is some past research evidence to suggest that failure severity can make a difference to how explanations are viewed. For example, Shapiro (1991) found that accounts were most effective under conditions of low outcome severity. Similarly, Conlon and Murray (1996) reported that satisfaction with an explanation decreased as outcome severity increased. While an apology may be satisfactory in a low severity event, a customer may expect a more detailed explanation when things fall well below expectations. In sum, it is expected that the severity of the service failure will influence how other information, such as an explanation, is evaluated. We investigated the relative efficiency of referential accounts versus justifications, as a function of severity of the service failure. Although previous research has not provided much insight to this, we believe that 
consumers are more likely to be concerned about their outcome relative to others (referential focus) in contrast to the well being of the company (justification focus). This is especially likely to be the case when the failure is more severe as the loss or consequence to the customer is greater, thus potentially more inequitable and dissatisfying (Smith et al, 1999). A referential explanation might help to minimize the feelings of inequity and thus satisfaction. Because a referential account provides a comparison to another customer who is worse off, the situation may appear relatively less severe.

Hypothesis 4: A referential explanation of a service failure will result in higher levels of customer satisfaction and intended loyalty than a justification when the service failure is especially severe.

As discussed earlier, account adequacy is expected to be an important mediating variable. In addition, past research has attempted, somewhat inconclusively, to determine whether perceived adequacy of an account is likely to be the same irrespective of outcome severity. Shapiro and Buttner (1988, cited in Shapiro, 1991) found account adequacy to be higher in low severity conditions compared to high severity conditions. That is, as a situation increases in seriousness, it may be more difficult to provide an adequate explanation.

Hypothesis 5: Account adequacy for a service failure is greater in contexts of low versus high outcome severity.

Finally, Fairness Theory (Folger \& Cropanzano, 1998) provides evidence that consumers will engage in more extensive thinking processes when events are negative. According to this theory, following a negative event, such as a service failure encounter, people tend to engage in a process referred to as "counterfactual thinking" (Roese, 1997). Put simply, counterfactual thinking refers to cognitions about the service incident that go beyond the facts (that is, imagined things that didn't actually happen, but that it is believed could have or should have happened). Therefore, when events 
are particularly negative (high failure severity), counterfactual thinking is likely to be high, and an explanation may possibly moderate the use of further counterfactual thinking, such as whether the event could have or should have been otherwise.

Hypothesis 6: Under the high severity condition an explanation of a service failure will reduce the level of counterfactual thinking

\section{METHOD}

\section{Research design}

The study adopted a between-subjects experimental design using written scenarios as the stimulus materials. Experimental scenarios have proved valuable in the study of reactions to service failures and/or recovery processes (e.g. Smith \& Bolton, 1998; Smith, Bolton, \& Wagner, 1999). Consumers read and evaluated a hotel service scenario, which described a service failure event. In order to select an appropriate service failure event that would be suitable across all conditions, we undertook pretests on what type of service failure would be suitable. This pretest phase involved constructing two service failure events (one hotel and one airline) and asking a range of individuals (colleagues and $\mathrm{PhD}$ scholars in tourism) to review these for credibility, realism and clarity. Based on this stage we selected a scenario that involved a service failure event triggered by overbooking. Three independent variables were manipulated: outcome severity (low, medium and high), type of account (justification or referential), and thoroughness of account (low or high). The twelve scenarios were identical except for manipulations of these variables.

In the scenario, a guest arrived at a hotel at which he/she had a booking, to find that their room was not available due to overbooking. In all versions, the service provider's gender and age were not revealed and the reason for staying at the hotel remained the same. As Smith and her colleagues (1999) point out, this method is useful when it is difficult to observe or replicate as an experiment in the field. 


\section{Measurement variables}

Following the scenario, a series of statements was presented seeking feelings or opinions on the service incident and its management. These constituted the dependent variables in the study. The key dependent variables included a measure of satisfaction, adapted from Oliver and Swan (1989) (6 items), and a measure of behavioral intent toward loyalty, adapted from Morgan and Hunt (1994) and Zeithaml, Berry and Parasuraman (1996) (7 items). Both variables were measured using multi-item scales measured on a seven point Likert-type scale ranging from Strongly Disagree (1) to Strongly Agree (7) with the mid point labeled as Neutral. Other variables used for the mediation analysis included perceptions of thoroughness (single item: I would have felt that I didn't get a thorough explanation - reversed coded) and assessments of the adequacy of the recovery tactics were measured using the same type of scale. The adequacy items (2 items) were similar to those used in past research (e.g., Bobocel et al., 1998; Gilliland et al., 2001), "I would think the reason the front desk clerk gave to me for the service problem was adequate" and "I would think the reason the front desk clerk gave to me for the service problem was sufficient”. Finally, we included two single-item measures to investigate counterfactual thinking: what could have and should have been done in the service failure/recovery event. These two single items were worded as follows: "The front desk clerk could have done more to resolve this service problem" and "The front desk clerk should have done more to resolve this service problem". All items were measured on a seven point Likert-type scale ranging from Strongly Disagree (1) to Strongly Agree (7) with the mid point labeled as Neutral. See Table 1 for an overview of the questions used in the study. The use of single item measures is often regarded an unacceptable in academic research primarily because these measures are presumed to have low reliability. However, some authors have argued that in some instances, particularly where the construct is relatively unambiguous, that this is not the case (Sackett and Larson, 1990). Similarly, Wanous, Reichers and Hudy (1997) suggest several conditions under which single items scales may be suitable. For instance, 
when there are situational constraints such as when space in a questionnaire is limited or where research budget is limited might suggest the use of a single item measure. Multi item scales were used in this study where the construct was relatively complex, while single items were used for constructs, which were considered explicit.

\section{Insert Table 1 about here}

\section{Sample and data collection method}

A sample comprising 5000 community members was randomly selected from a propriety list containing people who had previously experienced staying in luxury hotels in Australia. The sample was divided into 12 groups (eight with 417 members and four with 416) and the questionnaire was administered via a postal survey on a random allocation basis. The members of each group were sent a survey containing a booklet, which compromised one of the twelve scenarios, followed by a questionnaire. A cover letter was included in the package along with an information sheet with instructions and details of ethical clearance. Each respondent was provided with a return, reply paid envelope. By way of an incentive, respondents were offered an opportunity to go into a draw to win one of three shopping vouchers. Of the 5000 members selected, 2523 responded, representing a response rate of $50.46 \%$.

\section{RESULTS}

Prior to analysis, reverse scale items were recoded, and multi-item dependent variables were constructed by averaging across the items. Reliability coefficients were computed for the multiple item constructs: satisfaction ( 6 items) $\alpha 0.89$; loyalty ( 7 items) $\alpha .93$; and adequacy ( 2 items) $\alpha .83$. The distributions were examined and most dependent variables displayed high levels of positive skew due to a tendency by many respondents to select to lowest possible value in the scale. The methods used to address this problem are described in conjunction with the results of each analysis below. 


\section{Manipulation checks}

Checks of the realism (measured on a seven point scale) of the scenarios revealed that respondents generally believed that "there are service problems like this in real life" $(M=5.78, S D=$ 1.27), that "the scenario was believable" $(M=5.62, S D=1.21)$, and that they were "able to identify with the customer" $(M=5.67, S D=1.26)$.

Two of the independent variables were suitable for manipulation checking; outcome severity and thoroughness (both measured using a seven point scale). The former was tested using the statement "I felt that the service outcome was really bad". Using one-way ANOVA to compare the means of the three levels of outcome severity, it was found that there was significantly less agreement in the low severity condition than in the medium and high severity conditions, but no significant difference was observed between the medium and high conditions. This is in contrast to the results observed in a small pilot study where a clear distinction was observed between all levels. As result, a sub-set of the respondents (1667) is used in this paper to represent the low and high severity conditions and the medium severity condition was deleted from the analysis. Appendix 1 outlines the scenario and the manipulations of the variables used in this paper, which resulted in a total of eight cells each containing approximately 200 respondents.

In terms of thoroughness, using the item "I would have felt that I didn't get a thorough explanation", a t-test confirmed a significantly higher level of agreement with this statement for the low thoroughness condition $\left(t_{(1665)}=7.04, p<0.001 ; M=4.57 S D=1.75 \& 3.95, S D=1.87\right.$, respectively). This variable was reversed coded for further analyses. 


\section{The impact of the manipulations on the satisfaction and loyalty}

A 2 (severity) x 2 (thoroughness) x 2 (account type) factorial MANOVA was used to test mean differences in satisfaction and loyalty in each of the eight conditions. The MANOVA provides a test for hypotheses one, two and four. The summated scores of these two dependent variables exhibited high levels of positive skew. Factorial MANOVA, assumes multivariate normality, but it is suggested that violations of this assumption are not serious except to the extent that they make it difficult to apply the Box test (of covariance homogeneity) (Hair, Anderson, Tatham \& Black, 1995)

Log transformations were undertaken for each of the variables. This improved the distributions and facilitated a non-significant result $(p>0.01)$ in the Box test. The MANOVA was run with both the transformed and raw scores, and given the similarity in results, the raw score solution is presented as it retains the original properties of the scale. This MANOVA revealed a significant multivariate main effect for outcome severity and type of account, as well as an interaction effect between outcome severity and type of account (see Table 2 for details). All other main effects and interactions were non significant.

\section{Insert Table 2 about here}

For the main effect of outcome severity, significant univariate effects were found for both satisfaction and loyalty. In both cases the mean scores were higher when outcome severity was low (satisfaction $\mathrm{M}=2.77(\mathrm{SD}=1.27) \& \mathrm{M}=1.96(\mathrm{SD}=1.01)$; loyalty $\mathrm{M}=2.80(\mathrm{SD}=1.23) \& 1.94(.92))$. For the main effect of type of account, significant effects were found for the univariate variable of satisfaction only, providing partial support for hypothesis one. The mean score was higher when a referential account was given compared to a justification account (satisfaction $\mathrm{M}=2.45(\mathrm{SD}=1.25) \&$ $\mathrm{M}=2.26(\mathrm{SD}=1.17)$, respectively). Univariate tests revealed that the effect of the interaction between outcome severity and type of account was significant on both dependent variables, providing support 
for hypothesis four. Figure 1 displays the pattern of the interaction effect for each variable. As can be seen, there is no significant difference between the means in the low severity condition for either satisfaction or loyalty $(\mathrm{p}>.05)$. In contrast, under the high severity condition, a referential account resulted in a higher mean score than did a justification for both satisfaction $(\mathrm{M}=2.12(\mathrm{SD}=1.13)$ vs $1.81(\mathrm{SD}=.87)$, respectively $)$ and loyalty $(\mathrm{M}=2.03(\mathrm{SD}=1.02)$ vs $1.85(\mathrm{SD}=.82)$, respectively). As there was no significant main effect for the manipulation of thoroughness on satisfaction or loyalty, hypothesis two was rejected.

\section{Insert Figure 1 about here}

\section{Mediation Analyses}

Hypothesis 3 predicted that the relationships between explanation type and customer satisfaction evaluations would be mediated by account adequacy. This hypothesis was tested using standard multiple regression analyses, as recommended by Baron and Kenny (1986). The correlation matrix for the variables used in these analyses is shown in Table 3, organized by level of severity.

\section{Insert Table 3 about here}

Baron and Kenny (1986) recommend a series of regression models to establish mediation. First, the mediator (in this case adequacy) is regressed onto the independent variable (thoroughness), and a significant influence of thoroughness on the mediator should be present (equation 1). Second, the DV (satisfaction) is regressed onto the independent variable (thoroughness), and a significant effect of thoroughness on the DV should hold (equation 2). Third, the DV is regressed onto the independent variable and mediator combined. In this equation, the mediator must affect the DV, and the effect of 
thoroughness on the DV should be less than in the second equation (equation 3). Analyses were conducted separately for conditions of high and low severity.

As can be seen by the data presented in Table 4, account adequacy mediated the relationship between account thoroughness and consumer satisfaction in low and high severity conditions. In both severity conditions the beta weight reduced considerably from highly significant in equation 2 to nonsignificant in equation 3 (beta values .29 to .04 and .25 to .06 , respectively). In order to check that a reversing of the independent variable and mediator variable did not result in a better fit we ran the analyses for such a design (not shown in the table). The alternative model involving adequacy as the independent variable and thoroughness as the mediator showed no evidence of mediation. In the low severity condition, the beta for adequacy reduced minimally from .59 (in equation 2 ) to .57 (in equation 3), whereas the corresponding betas in the high severity condition were .47 (in equation 2 ) to .44 (in equation 3). See Figure 2 for an illustration of the mediation effect. The mediation analyses were also run separately under the two account type conditions (justification and referential), and similar results to those shown for severity emerged, further demonstrating the mediating role of account adequacy.

\section{Insert Table 4 about here Insert Figure 2 about here}

Given the importance of account adequacy, and hypothesis five, we followed up to test whether the perceived adequacy of an account would be higher in the low or high severity situation. The results of a one-way ANOVA, with severity as the independent variable and account adequacy as the dependent variable, revealed that an account was more likely to be perceived as adequate when the outcome severity was low rather than high $(\mathrm{F}(1,1664)=40.47 ; \mathrm{M}=3.20(\mathrm{SD}=1.66))$ vs $2.70(\mathrm{SD}=$ 1.57), respectively). 
Finally, in line with hypothesis six, we followed up on characteristics of the evaluation of the two forms of explanations, within the high severity condition. Specifically, we were interested to determine whether one type of account would result in assessments of a customer believing there were alternatives (a "could" counterfactual) and feeling something more ought to have been done (a "should" counterfactual). To test this we conducted a one-way ANOVA using the high severity condition only, with account type as the independent variable and two types of counterfactuals as dependent variables. Results of the one-way ANOVA revealed that there was a significant difference for the explanation types on these two counterfactuals (should not have done more $-F(1,838)=$ $22.53, p=.000$; could not have done more $-F(1,842)=15.45, \mathrm{p}=.000)$. Referential accounts were less likely to invoke counterfactual thinking compared to justifications (should not have done more Ms $=2.77$ vs $2.34 \&$ could not have done more Ms $=3.12$ vs 2.73 ). However, consumers in both cases thought more could have and should have been done; that is neither explanation moderated the situation to the extent that there was no counterfactual thinking. Table 5 provides a summary of the results for each hypothesis.

\section{Insert Table 5 about here}

\section{DISCUSSION AND CONCLUSION}

As was anticipated, more severe service failures lead to lower levels of satisfaction and loyalty. Outcome severity appears to explain more of the variation in the dependent variables than other manipulations included in the study. In addition, the results indicate that when service failure occurs, variation in the type of explanation offered by service providers can result in different impacts on satisfaction and feelings of loyalty. Thoroughness did not directly impact satisfaction or loyalty but 
evidence suggests perceptions of thoroughness have an indirect effect via the mediating role of account adequacy.

In all cases, referential accounts appeared to be more effective than justification accounts. It is argued that this is because a comparison is made to the less favorable outcomes for others is akin to a retrospective lowering of expectations. It may also appeal to customers' sense of distributive justice. Simply knowing that their outcomes were better than others seemed to satisfy respondents, they did not appear to require a thorough explanation of why the service failure had occurred. The group value theory (Tyler \& Lind,1992) also sheds some light onto this. Based on this theory it can be asserted that consumers value an outcome because it signals information about their standing, status or value within a group, in this case that of valued hotel consumer. Thus, service recovery tactics that enhance the perception that a customer is of value to the hospitality firm, during the management of a service failure event, are likely to increase feelings of customer satisfaction.

Importantly, it seems that in a service failure event that is more severe (has a worse outcome) people attend even more to the explanation content. We found a differential effect for explanation type under different levels of severity. While any explanation seems satisfactory in time of a minor service failure, the referential explanation was more efficacious in times of high severity of failure. Moreover, at times of high severity the referential account seems to reduce the strength of could and should counterfactuals. That is, consumers tended to feel more could have and should have been done to alleviate the negative aspects of the situation when as justification was provided compared to the referential account. Our results lend support to Fairness Theory’s (Folger \& Cropanzano, 1998) prediction that an explanation can potentially deactivate counterfactual thinking. The more effective the explanation, the less likely are people to imagine alternative or better solutions to the service failure. Finally, the pattern of outcome severity by explanation interaction effect is consistent with the 
fair process effect, whereby process information (such as an explanation) influences how an outcome is perceived. In the more unfavorable outcome (high severity) condition, the outcome has less negative repercussions when the referential explanation is provided, compared to the justification.

As predicted in Folger and Cropanzano's (1998) model of social accounts, account adequacy played a significant role in mediating the effect of perceived thoroughness of account. It would appear important that, for an account to be effective, it must be seen to be adequate. This lends further support to the recent meta-analysis by Shaw et al. (2003) where it was noted that the adequacy of an explanation (i.e., the degree to which it is clear, reasonable, and detailed) directly affects various attitudinal and behavioral outcomes. Furthermore, they found that explanation adequacy was more important than the explanation itself. Perceived thoroughness of the explanation provided to a customer directly influenced the perceptions of adequacy. Given that adequacy played an important mediating role, future research could do more to investigate dimensions of explanations, other than thoroughness, that lead to greater perceptions of adequacy. For instance, the logic and content details of the explanation might lead to greater level of adequacy. Similarly, more research could focus on the person delivering the explanation. Past research (Sitkin \& Bies, 1993) has suggested that the perceived sincerity of the account giver could influence the effectiveness of an account.

From a practitioner's viewpoint this study offers some further insight to service recovery management. First, training front line staff on the importance of supplying an explanation that is perceived as adequate is required. Since adequacy is an important mechanism through which customer satisfaction is derived, it is important that front line staff understand this and gain some sort of understanding of what is adequate in the mind of the customer. Second, an awareness that all explanations are not equal is useful and, while requiring further research, an explanation that reframes the outcome may have 
some benefits in managing service recovery. Third, when failure is severe, the use of a referential explanation resulted in $10 \%$ more of the respondents providing a rating of neutral or higher in satisfaction levels compared with the justification.

This study has provided some insights into the use of accounts in mitigating the impacts of service failure. In summary, we found that explanations do matter, a referential or reframing explanation worked better than a justification, a referential explanation decreased counterfactual thinking, explanations played a more important role in conditions of high failure severity, and the adequacy of the explanation mediated the effects of account thoroughness. To extend this research, application of other types of explanations could be considered, such as including excuses or an apology manipulation. Also, the inclusion of other variables, such as compensation, which is likely to have a much more substantial effect on service recovery should be considered. Explanations are provided in response to complaints and further research could investigate the likely moderating effect of the medium used to deliver an explanation, for instance, written versus spoken explanation. Given the vital importance of managing negative service events, managers and researchers in the tourism and hospitality field should be cognizant of the need to build a more substantial theory of the use of explanations.

\section{Limitations}

A limitation of our research includes the use of projective, role-playing scenarios that might reduce the external validity of the findings (Barling \& Phillips, 1993). However, the scenario method has been used effectively in previous research on service encounters because of its advantages over other methods in terms of feasibility, economy, control, and the ethics of research. Its limitations, particularly in relation to ecological and external validity, are also well known (see, e.g., Smith et al., 
1999). In addition, findings from our research may not generalize beyond the hospitality context and problem type depicted. It must be acknowledged that the context and the content of the explanation may directly contribute to the results and other explanations, whether they justification or explanations, may lead to different results. For example, whether the justification is primarily firm based (e.g. the firm would go broke) or customer based (e.g. we would have to charge customer more if we did not adopt this policy) could influence the customer evaluation. Thus, as indicated earlier further research must be done to expand on the content of the explanations that will be most effective. Furthermore, the addition of manipulation checks for the explanations could be undertaken in future research. We acknowledge that the scenario of overbooking may not perfectly reflect what would happen in a real situation and alternative scenarios need to be tested in future. The authors did not follow up on nonrespondents and this may be a limitation of the present study as it is unknown whether this group differs from those who responded. Finally, replications using other methods, samples, measures (including multiple items), and hospitality contexts are advocated for future research. More specifically, conducting a field study whereby respondents recall a critical incident where an explanation was provided would allow for classification into explanation types and further investigation, thus providing an opportunity to identify a typology of effective explanations. Contexts other than hotels could also be investigated in the same manner. This study used single item measures for some constructs, which may not precisely represent the true meaning of the construct. Future research should address this problem by using multiple items so that any error arising from ambiguities or bias can be more effectively cancelled out (Wegener \& Fabrigar, 2004). In conclusion, the area of managing service failure events through explanations offers a promising field for researchers but more work is needed. 


\section{REFERENCES}

Barling, J., \& Phillips, M. (1993). Interactional, formal, and distributive justice in the workplace: An exploratory study. Journal of Psychology, 127, 649-656.

Baron, R. M., \&. Kenny D. A. (1986). The Moderator-Mediator Variable Distinctions in Social Psychological Research: Conceptual, Strategic, and Statistical Considerations, Journal of Personality and Social Psychology, 51, 1173-1182.

Bies, R. J. (1987). The predicament of injustice: The management of moral outrage. In B. M. Staw \& L. L. Cummings (Eds.), Research in organizational behavior. Volume 9 (pp. 289-319). New York: JAI Press.

Blodgett, J. G., Hill, D. J., \& Tax, S. S. (1997). The effects of distributive, procedural, and interactional justice on postcomplaint behavior. Journal of Retailing, 73(2), 185-210.

Bobocel, D. R., \& Zdaniuk, A (2005). How can explanations be used to foster organizational justice? In Greenberg, J. \& Colquitt, J. A. (Eds.) Handbook of Organizational Justice. Lawrence Erlbaum Associates, New Jersey.

Bobocel, D. R., Agar, S. E., Meyer, J. P., \& Irving, P. G. (1998). Managerial accounts and fairness perceptions in conflict resolution: Differentiating the effects of minimizing responsibility and providing justification. Basic and Applied Social Psychology, 20(2), 133-143.

Butcher, K., \& Heffernan, T. (2006). Social regard: a link between waiting for service and service outcomes. International Journal of Hospitality Management, 25, 34-53.

Conlon, D. E., \& Murray, N. M. (1996). Customer perceptions of corporate responses to product complaints: The role of explanations. Academy of Management Journal, 39(4), 1040-1056.

Davidow, M. (2000). The bottom line impact of organizational responses to customer complaints. Journal of Hospitality and Tourism Research, 24(4), 473-490. 
Davidow, M. (2003). Organizational responses to customer complaints: What works and what doesn't. Journal of Service Research, 5(3), 225-250.

Folger, R., \& Cropanzano, R. (1998). Organizational justice and human resource management. Thousand Oaks, CA: Sage

Gilliland, S. W., Groth, M., Baker, R. C., Dew, A., Polly, L. M., \& Langdon, J. C. (2001). Improving applicants' reactions to rejection letters: An application of Fairness theory. Personnel Psychology, 54 (3), 669-703.

Greenberg, J. (1994). Using socially fair treatment to promote acceptance of a work site smoking ban. Journal of Applied Social Psychology, 79, 288-297.

Hair, J. F., Anderson, R. E., Tatham, R. L., \& Black, W. C. (1995). Multivariate Data Analysis, 4th Ed. Englewood Cliffs: Prentice Hall.

Karatepe, O. M. (2006). Customer complaints and organizational responses: the effects of complainants' perceptions of justice on satisfaction and loyalty. International Journal of Hospitality Management, 25, 69-90.

Keaveney, S. M. (1995). Customer switching behavior in service industries: An exploratory study. Journal of Marketing, 59(April), 71-82.

Matilla, A. S. (1999). An examination of the factors affecting service recovery in a restaurant setting. Journal of Hospitality and Tourism Research, 23(3), 284-298

Mc Coll-Kennedy, J. R., \& Sparks, B. A. (2003). Application of Fairness Theory to service failures and service recovery, Journal of Service Research, 5 (3) 251-266.

Morgan, R. M., \& Hunt, S. D. (1994). The commitment trust theory of relationship marketing, Journal of Marketing, 58, 20-38.

Ok, , C., Back, K., \& Shankin, C. W. (2005). Modeling roles of service recovery strategy: A relationship focused view. Journal of Hospitality and Tourism Research, 29, 484-507. 
Oliver, R. L., \& Swan, J. E. (1989). Consumer perceptions of interpersonal equity and satisfaction in transactions: A field survey approach. Journal of Marketing, 53 (2), 21-35.

Roese, N. J. (1997). Counterfactual thinking. Psychological Bulletin, 121(1), 133-148.

Sackett, P. R., \& Larson, J. R., Jr. (1990). Research strategies and tactics in industrial and organizational psychology. In M. D. Dunnette \& L. M. Hough (Eds.), Handbook of industrial and organizational psychology (2nd ed., Vol. 1, pp. 419-489). Palo Alto, CA: Consulting Psychologists Press.

Shapiro, D. L. (1991). The effects of explanations on negative reactions to deceit. Administrative Science Quarterly, 36, 614-630.

Shapiro, D. L., Buttner, E. H., \& Barry, B. (1994). Explanations: What factors enhance their perceived adequacy? Organizational Behavior and Human Decision Processes, 58, 346-368.

Shaw, J. C., Wild, E., \& Colquitt, A. To justify or excuse?: A meta-analytic review of the effects of explanations. Journal of Applied Psychology, 88 (3), 444-458.

Sitkins, S. B. \& Bies, R. J. (1993). Social accounts in conflict situations: Using explanations to manage conflict. Human Relations, 46, 349-370.

Smith, A. K., \& Bolton, R. N. (1998). An experimental investigation of customer reactions to service failure and recovery encounters: Paradox or peril? Journal of Service Research, 1(1), 65-81.

Smith, A. K., Bolton, R. N., \& Wagner, J. (1999). A model of customer satisfaction with service encounters involving failure and recovery. Journal of Marketing Research, 36, 356-372.

Sparks, B. A., \& Callan, V. J. (1996). Service breakdowns and service evaluations: The intervening role of attributions. Journal of Hospitality and Leisure Research, 4(2),3-24.

Tyler, T.R, \& Lind, E.A. (1992). A relational model of authority in groups. In M. P. Zanna (Ed.) Advances in experimental social psychology. San Diego, CA: Academic Press. 
Wanous, J. P., Reichers, A. E. \& Hudy, M.J. (1997). Overall Job Satisfaction: How Good are Single Item Measures. Journal of Applied Psychology, 82, 247-252.

Wegener, D. T. \& Fabrigar, L. R. (2004). Constructing and evaluating quantitative measures for social psychological research: Conceptual challenges and methodological solutions. In C. Sansone, C. C. Morf \& A. T. Panter, Handbook of Methods in Social Psychology. Thousand Oaks: Sage.

Zeithaml, V. A., Berry, L. \& Parasuraman, A. (1996). The behavioural consequences of service quality. Journal of Marketing, 60, 31-46. 
Table 1 Items used in the study

\section{Satisfaction items - six items}

I would feel extremely displeased with the service $(R)$

I would feel extremely contented with the service.

I would feel that the hotel did an extremely poor job $(R)$

I feel that I had made an extremely wise choice in buying from that hotel.

I feel extremely unhappy with this hotel. (R)

I feel extremely dissatisfied with this hotel. (R)

\section{Loyalty Items - seven items}

I would say positive things about this hotel to other people.

I would stay in this hotel the next time I was visiting that city.

I would still have trust in the hotel.

I would recommend this hotel to other people.

I would consider this hotel as my first choice to stay next time I was visiting that region.

I would encourage friends and relatives to do business with this hotel.

I would still consider that this hotel was basically honest.

\section{Could counferfactual - single item}

The front desk clerk could have done more to resolve this service problem.

\section{Should counferfactual - single item}

The front desk clerk should have done more to resolve this service problem 
Thoroughness - single item

I would have felt that I didn't get a thorough explanation

Adequacy - two items

I would think the reason the front desk clerk gave to me for the service problem was

adequate

I would think the reason the front desk clerk gave to me for the service problem was sufficient

Note: All items measured on a seven point Likert type scale with 7 indicating more agreement 
Table 2 MANOVA results

\begin{tabular}{|c|c|c|c|}
\hline Effect & $\begin{array}{l}\text { Multivariate test } \\
\text { (Wilks' lambda) }\end{array}$ & Variable & Univariate test \\
\hline \multirow[t]{2}{*}{$\begin{array}{l}\text { Outcome } \\
\text { Severity (OS) }\end{array}$} & $\mathrm{F}_{(2,1644)}=131.1, p<0.05, \eta^{2}=.138$ & Satisfaction & $\begin{array}{l}\mathrm{F}_{(1,1652)}=203.66, p=.000 \\
\eta^{2}=.110\end{array}$ \\
\hline & & Loyalty & $\begin{array}{l}\mathrm{F}_{(1,1652)}=260.53 p=.000 \\
\eta^{2}=.137\end{array}$ \\
\hline \multirow{2}{*}{$\begin{array}{l}\text { Thoroughness } \\
\text { (TH) }\end{array}$} & $\mathrm{F}_{(2,1644)}=1.52, p=.219, \eta^{2}=.002$ & Satisfaction & \\
\hline & & Loyalty & \\
\hline \multirow[t]{2}{*}{$\begin{array}{l}\text { Type of } \\
\text { Account (AC) }\end{array}$} & $\mathrm{F}_{(2,1644)}=6.89, p=.001, \eta^{2}=.008$ & Satisfaction & $\begin{array}{l}\mathrm{F}_{(1,1652)}=8.81, p=.003 \\
\eta^{2}=.005\end{array}$ \\
\hline & & Loyalty & $\begin{array}{l}\mathrm{F}_{(1,1652)}=1.62, p=.203 \\
\eta^{2}=.001\end{array}$ \\
\hline $\mathrm{OS} * \mathrm{TH}$ & $\mathrm{F}_{(2,1644)}=.39, p=.678, \eta^{2}=.000$ & $\begin{array}{l}\text { Satisfaction } \\
\text { Loyalty }\end{array}$ & \\
\hline \multirow[t]{2}{*}{$\mathrm{OS} * \mathrm{AC}$} & $\mathrm{F}_{(2,1644)}=3.14, p=.044, \eta^{2}=.004$ & Satisfaction & $\begin{array}{l}\mathrm{F}_{(1,1652)}=6.28, p=.012 \\
\eta^{2}=.004\end{array}$ \\
\hline & & Loyalty & $\begin{array}{l}\mathrm{F}_{(1,1652)}=4.29, p=.038 \\
\eta^{2}=.003\end{array}$ \\
\hline $\mathrm{TH}^{*} \mathrm{AC}$ & $\mathrm{F}_{(2,1644)}=1.28, p=.278, \eta^{2}=.002$ & $\begin{array}{l}\text { Satisfaction } \\
\text { Loyalty }\end{array}$ & \\
\hline $\mathrm{OS} * \mathrm{TH}^{*} \mathrm{AC}$ & $\mathrm{F}_{(2,1644)}=0.58, p=.562, \eta^{2}=.001$ & $\begin{array}{l}\text { Satisfaction } \\
\text { Loyalty }\end{array}$ & \\
\hline
\end{tabular}


Table 3 Descriptive statistics and bivariate correlations $(\mathrm{N}=1667)$

\begin{tabular}{|c|c|c|c|c|c|}
\hline Variable & $\begin{array}{l}\text { No. } \\
\text { of } \\
\text { items }\end{array}$ & $M$ & $S D$ & $\begin{array}{l}\text { Perceived } \\
\text { thoroughness }\end{array}$ & Adequacy \\
\hline \multicolumn{6}{|c|}{ Low severity $(\mathrm{N}=822)$} \\
\hline $\begin{array}{l}\text { Perceived } \\
\text { thoroughness }\end{array}$ & 1 & 4.00 & 1.77 & & \\
\hline Adequacy & 2 & 3.20 & 1.66 & $.44 * *$ & \\
\hline Satisfaction & 6 & 2.77 & 1.27 & $.29 * *$ & $.60 * *$ \\
\hline \multicolumn{6}{|c|}{ High severity $(\mathrm{N}=845)$} \\
\hline $\begin{array}{l}\text { Perceived } \\
\text { thoroughness }\end{array}$ & 1 & 3.48 & 1.86 & & \\
\hline Adequacy & 2 & 2.70 & 1.57 & $.44^{* *}$ & \\
\hline Satisfaction & 6 & 1.96 & 1.01 & $.25^{* *}$ & $.47 * *$ \\
\hline
\end{tabular}


Table 4 Regression equations testing mediation model linkages

\begin{tabular}{|c|c|c|c|c|c|c|}
\hline \multirow{2}{*}{$\begin{array}{l}\text { Variables in } \\
\text { regression equation }\end{array}$} & \multicolumn{3}{|c|}{ Low severity Condition } & \multicolumn{3}{|c|}{ High severity Condition } \\
\hline & Adj $r^{2}$ & $\beta$ & $\mathrm{t}$ value & Adj $r^{2}$ & $\beta$ & $\mathrm{t}$ value \\
\hline & \multicolumn{6}{|c|}{ DV: Customer satisfaction } \\
\hline \multicolumn{7}{|l|}{ EQUATION 1} \\
\hline Perceived & $.18^{* * *}$ & 0.44 & $14.18^{* * *}$ & $.19 * * *$ & 0.44 & $14.23 * * *$ \\
\hline \multicolumn{7}{|l|}{ Thoroughness=>adequacy } \\
\hline \multicolumn{7}{|l|}{ EQUATION 2} \\
\hline \multicolumn{7}{|l|}{$=>$ satisfaction } \\
\hline \multicolumn{7}{|l|}{ EQUATION 3} \\
\hline $\begin{array}{l}\text { Perceived Thoroughness }+ \\
\text { adequacy }=>\text { satisfaction }\end{array}$ & $.35 * * *$ & & & $.22 * * *$ & & \\
\hline Adequacy & & 0.57 & $18.13 * * *$ & & 0.44 & $13.08 * * *$ \\
\hline Perceived Thoroughness & & 0.04 & $1.20(\mathrm{~ns})$ & & 0.06 & $1.64(\mathrm{~ns})$ \\
\hline
\end{tabular}


Table 5 Summary hypothesis outcomes

\begin{tabular}{lll}
\hline Hypothesis & Test & Outcome \\
\hline $\begin{array}{l}\text { 1: A referential explanation of a service failure will have a } \\
\text { different impact on customer evaluations of customer } \\
\text { satisfaction and intended loyalty than a justification }\end{array}$ & MANOVA & $\begin{array}{l}\text { Supported for } \\
\text { satisfaction only }\end{array}$ \\
2: More thorough accounts of a service failure will result in & MANOVA & Not supported \\
higher levels of customer satisfaction and intended loyalty & & Supported \\
$\begin{array}{l}\text { 3: Perceived levels of thoroughness of a service failure } \\
\text { explanation will significantly influence ratings of consumer } \\
\text { satisfaction through the mediating factor of account adequacy }\end{array}$ & & \\
$\begin{array}{l}\text { 4: A referential explanation of a service failure will result in } \\
\text { higher levels of customer satisfaction and intended loyalty than } \\
\text { a justification when the service failure is especially severe }\end{array}$ & MANOVA & Supported \\
$\begin{array}{l}\text { 5: Account adequacy for a service failure is greater in contexts } \\
\text { of low versus high outcome severity }\end{array}$ & ANOVA & Supported \\
$\begin{array}{l}\text { 6: Under the high severity condition an explanation of a service } \\
\text { failure will reduce the level of counterfactual thinking }\end{array}$ & ANOVA & Supported \\
\hline
\end{tabular}




\section{Estimated Marginal Means of Satisfaction}

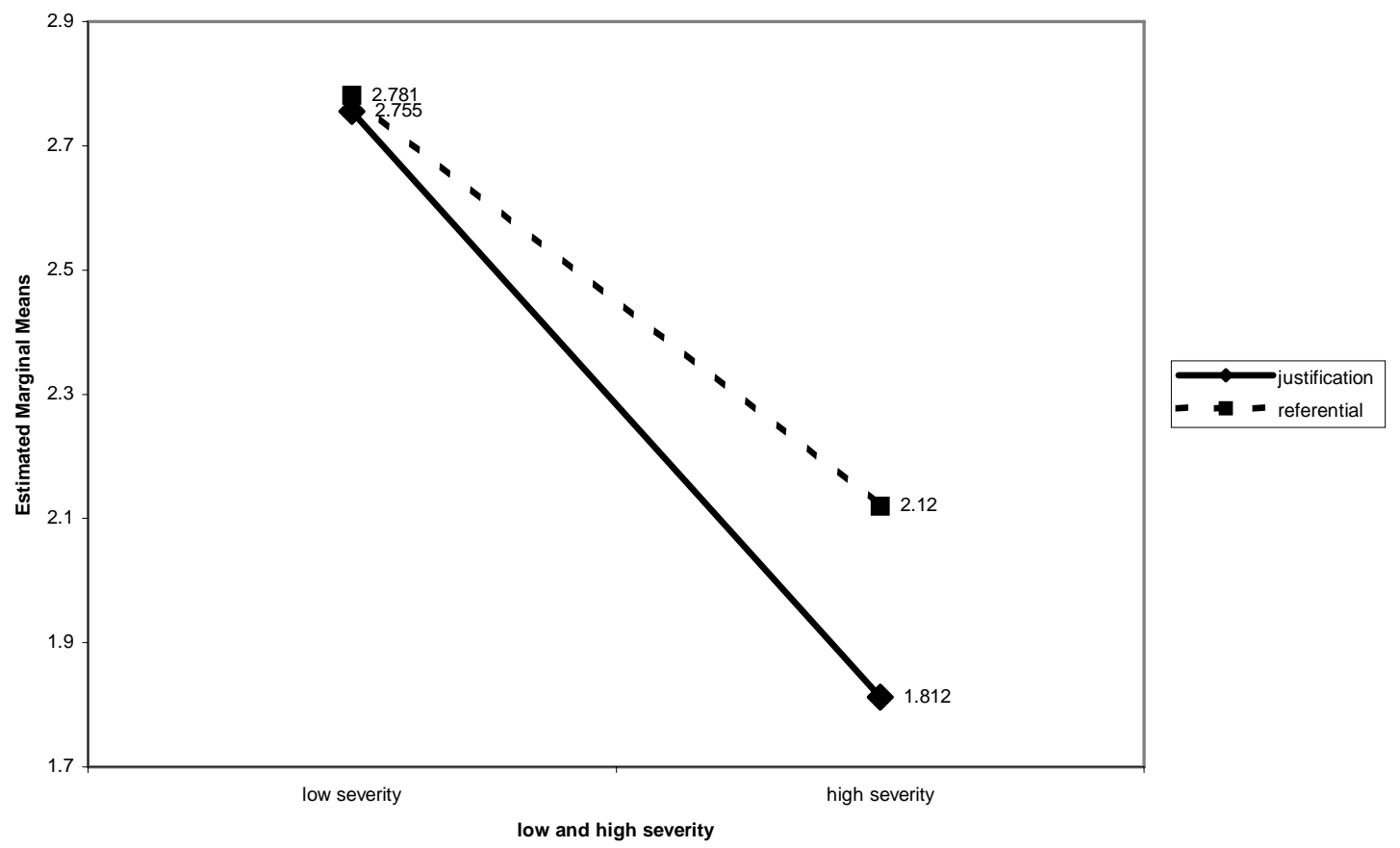

\section{Estimated Marginal Means of Loyalty}

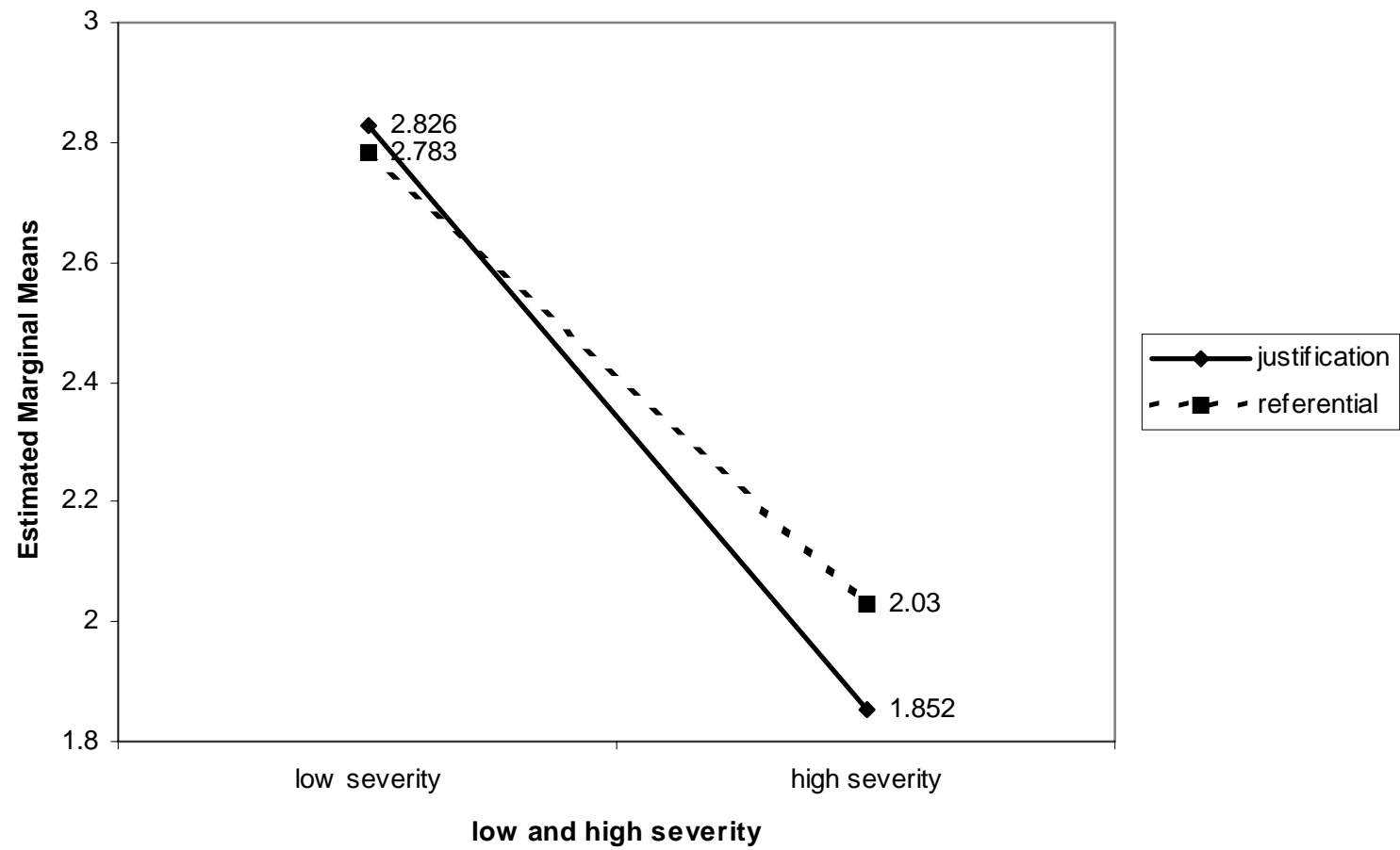

Figure 1 Graphs for interaction effect severity and type of explanation 


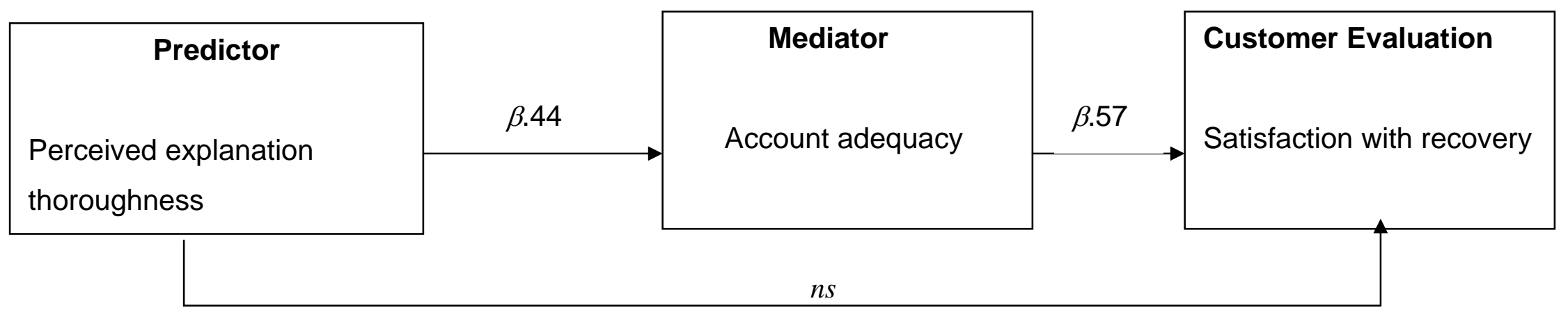

Figure 2 Final mediation model - low severity condition 
Appendix 1 The scenario with all conditions used in this study INTRODUCTION

In service industries such as hotels, airlines, banks or restaurants there is always a chance of things not going as planned. In this study we are concerned about your views on how a service problem in a hotel should be handled. We are interested in your own opinions. We would like you to try and imagine yourself in the role of the customer. There are no right or wrong answers.

Imagine the following situation.

Following a two-hour flight, you have just arrived at a hotel in a city centre where you will be attending a High School reunion for the next two days. The hotel is a nice five star property but you haven't stayed there before. It is $4 \mathrm{pm}$ in the afternoon and you are looking forward to getting to your room so you can change and get to the reunion drinks at $6 \mathrm{pm}$. You make your way to the front desk and stand in queue about five minutes before being greeted by the front desk clerk. You go up to the desk and provide your name and indicate that you are checking in.

The desk clerk seeks out your booking and responds as follows:

OUTCOME SEVERITY ${ }^{3}$ - part one

Low "I'm terribly sorry but the hotel room is not ready, as we are overbooked. It seems the room won't be ready until 5pm."

High "I'm terribly sorry but the hotel room is not ready just yet, as we are overbooked. It seems the room won't be ready until tomorrow morning."

\section{TYPE OF ACCOUNT}

\section{Justification}

The clerk goes on to explain. "Look, I'm really sorry this has happened to you, we have to overbook as so many people cancel these days. If we didn't do this we'd go broke."

\section{Referential}

The clerk goes on to explain. 'Look, I'm really sorry this has happened to you but you're actually a lot better off than other guests. At least I can get you a room in an hour [high severity: ... room at another hotel]. I can't do as well for guests arriving later today."

\section{THOROUGNESS OF ACCOUNT}

\section{Low}

"Overbooking is a procedure used by most hotels."

\section{OUTCOME SEVERITY - part two (at end of scenario)}

\section{Low}

The desk clerk finalises arrangements and you wait an hour before getting the key to your room. You go upstairs and manage to unpack and freshen up in time for the reunion drinks with very little inconvenience.

\section{High}

"Overbooking is a procedure most hotels use in an effort to balance out the people who don't turn up. Based on our hotel history, we know that around 25\% of our guests don't turn up. As a result, we usually overbook by $20 \%$. Usually the overbooking doesn't lead to any guest being inconvenienced too much."

\section{High}

The desk clerk finalises arrangements and you are transferred to another hotel to stay overnight. By the time you get across town to the hotel a couple of hours have passed and you end up missing the reunion drinks and you feel very inconvenienced.

\footnotetext{
${ }^{3}$ Note: As the medium level of severity was deleted from use in the analyses it is not included here. Please contact the first named author for a copy of this if required.
} 
